\title{
Limitations in the screening of potentially anti-cryptosporidial agents using laboratory rodents with gastric cryptosporidiosis
}

\author{
Andrea Valigurová ${ }^{1}$, Radka Pecková ${ }^{1}$, Karel Doležal ${ }^{2}$, Bohumil Sak ${ }^{3}$, Dana Květoňová ${ }^{3}$, Martin Kváč ${ }^{3,4}$, Wisnu \\ Nurcahyo ${ }^{5}$, Ivona Foitová ${ }^{1,5}$
}

\begin{abstract}
${ }^{1}$ Department of Botany and Zoology, Faculty of Science, Masaryk University, Brno, Czech Republic;
${ }^{2}$ Department of Chemical Biology and Genetics \& Laboratory of Growth Regulators, Centre of the Region Haná for Biotechnological and Agricultural Research, Faculty of Science, Palacký University, and Institute of Experimental Botany, Academy of Sciences of Czech Republic, Olomouc-Holice, Czech Republic;

${ }^{3}$ Institute of Parasitology, Biology Centre of the Czech Academy of Sciences, České Budějovice, Czech Republic;

${ }^{4}$ Department of Animal Husbandry Sciences, Faculty of Agriculture, University of South Bohemia in České Budějovice, Czech Republic;

${ }^{5}$ Department of Parasitology, Faculty of Veterinary Medicine, Gadjah Mada University, Yogyakarta, Indonesia
\end{abstract}

\begin{abstract}
The emergence of cryptosporidiosis, a zoonotic disease of the gastrointestinal and respiratory tract caused by Cryptosporidium Tyzzer, 1907, triggered numerous screening studies of various compounds for potential anti-cryptosporidial activity, the majority of which proved ineffective. Extracts of Indonesian plants, Piper betle and Diospyros sumatrana, were tested for potential anticryptosporidial activity using Mastomys coucha (Smith), experimentally inoculated with Cryptosporidium proliferans Kváč, Havrdová, Hlásková, Daňková, Kanděra, Ježková, Vítovec, Sak, Ortega, Xiao, Modrý, Chelladurai, Prantlová et McEvoy, 2016. None of the plant extracts tested showed significant activity against cryptosporidia; however, the results indicate that the following issues should be addressed in similar experimental studies. The monitoring of oocyst shedding during the entire experimental trial, supplemented with histological examination of affected gastric tissue at the time of treatment termination, revealed that similar studies are generally unreliable if evaluations of drug efficacy are based exclusively on oocyst shedding. Moreover, the reduction of oocyst shedding did not guarantee the eradication of cryptosporidia in treated individuals. For treatment trials performed on experimentally inoculated laboratory rodents, only animals in the advanced phase of cryptosporidiosis should be used for the correct interpretation of pathological alterations observed in affected tissue. All the solvents used (methanol, methanol-tetrahydrofuran and dimethylsulfoxid) were shown to be suitable for these studies, i.e. they did not exhibit negative effects on the subjects. The halofuginone lactate, routinely administered in intestinal cryptosporidiosis in calves, was shown to be ineffective against gastric cryptosporidiosis in mice caused by C. proliferans. In contrast, the control application of extract Arabidopsis thaliana, from which we had expected a neutral effect, turned out to have some positive impact on affected gastric tissue.
\end{abstract}

Keywords: Cryptosporidium, gastric, oocyst, pathology, treatment

The phylum Apicomplexa comprises exclusively parasitic protists infecting invertebrates and vertebrates, including humans. One of the most significant and widespread pathogens are coccidia of the genus Cryptosporidium Tyzzer, 1907, causative agents of zoonotic disease (cryptosporidiosis) of the gastrointestinal and respiratory tracts. In healthy hosts, cryptosporidiosis is self-limiting; nevertheless, in immunocompromised hosts, it represents a chronic and debilitating condition (Chen et al. 2002).

Although gastric cryptosporidia have been reported in fish, reptiles, amphibians, birds and mammals (Jirků et al. 2008, Ryan 2010, Nakamura and Meireles 2015), there is a dearth of useful studies dealing with the treatment of gastric cryptosporidiosis. In contrast to intestinal species, the course of gastric cryptosporidiosis in both immunocompetent and immunodeficient animals is an asymptomatic and chronic infection (Kváč et al. 2008, 2011). In humans, gastric involvement is reported to be very common in patients with cryptosporidiosis when combined with severe immunodepression (Rivasi et al. 1999).

The recently described species Cryptosporidium proliferans Kváč, Havrdová, Hlásková, Daňková, Kanděra, Ježková, Vítovec, Sak, Ortega, Xiao, Modrý, Chelladurai, Prantlová et McEvoy, 2016 (previously known as strain TS03 of Cryptosporidium muris Tyzzer, 1907), used in this study, develops exclusively in the glandular part of the stomach, similar to C. muris and Cryptosporidium andersoni Lindsay, Upton, Owens, Morgan, Mead et Blagburn, 
2000, with a life cycle corresponding to that of $C$. muris (see Tyzzer 1910, Melicherová et al. 2014, Kváč et al. 2016). Though C. proliferans had been considered identical with $C$. muris in previous years, their clinical courses of parasitisation in Mastomys coucha (Smith) differ considerably (Kváč et al. 2016). Compared to C. muris, rodents shed oocysts of $C$. proliferans for a much longer period and at a greater intensity, and only $C$. proliferans induces significant clinical and pathological changes, such as weight loss and massive proliferation of the gastric mucosa associated with a considerable increase in stomach weight (Kváč et al. 2016). The change in the ratio of glandular to non-glandular surfaces from $55: 45$ to $80: 20$, detected in $M$. coucha infected with $C$. proliferans, was not observed in C. muris infection (Kváč et al. 2016).

Cryptosporidiosis is recognised as a major medical concern as there is no effective treatment for either intestinal or gastric cryptosporidiosis (Fayer et al. 2000, Thompson et al. 2005). Numerous compounds have been screened in vitro and in vivo for potential anti-cryptosporidial activity, but the majority turned out to be ineffective and only a few agents have shown promise. The most commonly used drugs used against cryptosporidiosis include antibiotics (e.g. paromomycin or azithromycin) and halofuginone, which are partially effective. In contrast to chemotherapeutics, often with considerable side effects and a certain level of toxicity, the use of natural products or dietary supplements with anti-cryptosporidial activity could represent a new and safe approach to the effective pharmacological control of cryptosporidiosis. For example, L-arginine was shown to have a protective role during infection with Cryptosporidium parvum Tyzzer, 1912 in undernourished mice (Castro et al. 2012). Several studies have found probiotics to be effective against cryptosporidiosis in humans and animals, reporting prompt clinical improvement and resolution of the infection following treatment (Rotkiewicz et al. 2001, Pickerd and Tuthill 2004). Lactobacillus spp. significantly reduced the viability of oocysts of $C$. parvum (see Foster et al. 2003). Administration of exogenous agmatine seems to alter the metabolism of $C$. parvum enough to interfere with its ability to colonise the mammalian intestine (Moore et al. 2001). Mangiferin, widely distributed in higher plants and one of the constituents of folk medicines (Yoshimi et al. 2001), has significant anti-cryptosporidial activity comparable to the same dose $(100 \mathrm{mg} / \mathrm{kg} /$ day $)$ of paromomycin (Tarantino et al. 2004, Perrucci et al. 2006). Curcumin, which is active against a variety of diseases, was found to be effective against $C$. parvum in cell cultures (Shahiduzzaman et al. 2009).

Garlic (Allium sativum) appears to be a prophylactic and a promising therapeutic agent, as it successfully eradicated cryptosporidial oocysts from the faeces and intestines of infected immunocompetent mice that had received garlic two days before the experimental infection and continued for two weeks (Gaafar 2012). The administration of garlic to human HIV patients with chronic diarrhoea and confirmed cryptosporidiosis resulted in complete or partial remission (Fareed et al. 1996). Onion (Allium cepa) and cinnamon (Cinnamomum zeylanicum) oils also turned out to be effective against the infection with $C$. parvum in mice (Abu El Ezz et al. 2011). In contrast, an in vitro study using HCT-8 cells inoculated with $C$. andersoni did not confirm the significant inhibition of parasite growth when exposed to garlicin (antifungal component extracted from garlic) (Wu et al. 2011). The authors concluded that garlicin inhibits the growth of cryptosporidia in vivo by enhancing macrophage activity, rather than by exerting direct effects on the parasite. This study also showed anti-cryptosporidial activity of ginkgolic acids extracted from maidenhair tree (Ginkgo biloba) sarcotesta. With the exception of the prophylactic effect of garlic, however, none of these natural products were able to completely eradicate cryptosporidiosis.

As humans and orang-utans exhibit phylogenetic similarities (Grehan and Schwartz 2009), we focused on orangutans' feeding behaviour with an emphasis on specific plants consumed that would lead to a reduction in parasite infections. Recently we documented a secondary self-medication (the external application of a medicinal substance) in Bornean orang-utans (Morrogh-Bernard at al. 2017). These findings validate the anti-inflammatory properties of Dracaena cantleyi and its application to muscles and joints by orang-utans, and may serve as the first evidence for the deliberate external application of substances with bioactive potential for self-medication in great apes.

We selected few plants including Piper betle and Diospyros sumatrana with promising antiparasitic activity on the basis of behavioural data and decreases in parasite load (Foitová et al. 2010). Our analyses show a positive correlation between the prevalence of these plant species in orang-utan diets and the presence of parasites (based on the Jaccard index of known frequency in nature) that cannot be explained by their prevalence in the environment. The betel, $P$. betle, has been used as a medicinal plant in traditional medicine throughout South and South East Asia since ancient times. Experimental studies have revealed its wide and diverse biological and pharmacological effects (Pecková et al. 2018). Diospyros sumatrana has not yet been studied for pharmacological potential, but our study shows its possible potential.

This study aimed to test extracts of Indonesian plants selected by orang-utans for self-medication for potential anti-cryptosporidial activity, using a rodent host that had been experimentally inoculated with $C$. proliferans. The extract of Arabidopsis thaliana (the Eurasian plant routinely used as a model in research laboratories) was used as a control with an expected neutral effect. Halofuginone lactate (Halocur), an oral solution used for the treatment of cryptosporidiosis in calves, was tested for its potentially positive effect.

\section{MATERIALS AND METHODS}

\section{Preparation of plant extracts}

The dried leaves obtained from Piper betle (akar sirih), Diospyros sumatrana (kayu hitam) and Arabidopsis thaliana (thale cress) were homogenised to a fine powder in liquid nitrogen. Portions of the ground material ( $0.33 \mathrm{~g})$ were then extracted sep- 
arately in $10 \mathrm{ml}$ of water, methanol (methanol) or methanol-tetrahydrofurane (methanol-THF, $1: 1$ ). After 16 hours of extraction (overnight) at $-20^{\circ} \mathrm{C}$, the resulting homogenates were centrifuged $\left(26,000 \mathrm{~g}, 4^{\circ} \mathrm{C}, 20 \mathrm{~min}\right)$; the sediments were then re-extracted for one hour in the same way and centrifuged. Afterward, these two supernatants were pooled and dried in a vacuum at $35^{\circ} \mathrm{C}$, and then dissolved in $100 \mu 1$ of pure Dimethylsulfoxid (DMSO), except for samples dissolved in sterile water, which were further diluted in sterile water.

\section{The parasite used in this study}

The gastric species Cryptosporidium proliferans used in this study and our previous studies (Kváč et al. 2008, 2011, 2016 Melicherová et al. 2014, 2016) originated from a naturally infected East African mole rat Tachyoryctes splendens (Rüppell) and was kept in severe combined immunodeficiency (SCID) mice and southern multimammate mice (Mastomys coucha) under laboratory conditions

Laboratory animals and experimental inoculations with oocysts of Cryptosporidium proliferans.

Eight-week old M. coucha mice (Biology Centre, CAS, České Budějovice) were used for this study. To prevent environmental contamination with oocysts, each group of mice was housed in plastic cages with sterile wood-chip bedding and supplied with sterilised food and water ad libitum. The rearing of animals was regulated by Czech legislation (Act No. 246/1992 Coll., on protection of animals against cruelty); these documents are consistent with legislation by the European Commission. All housing, feeding, and experimental procedures were conducted under protocols approved by the Institute of Parasitology, Biology Centre, CAS and Institute and National Committees (Protocols No. $52 / 2014)$.

For the experimental inoculation of mice, oocysts collected from faeces were purified using Sheather's sugar flotation method (Arrowood and Sterling 1987) and modified caesium chloride gradient centrifugation (Kilani and Sekla 1987). Each mouse was inoculated orally by an oesophagus tube with a dose of 106 viable oocysts of $C$. proliferans. Afterwards, fresh mouse faeces were collected daily in the morning and examined microscopically for the presence of oocysts using staining according to Miláček and Vítovec (1985). The intensity of oocyst excretion was assessed as the number of oocysts per gram of faeces (OPG) as previously described Kváč et al. (2007). In addition, faecal consistency, faecal colour and general health status were examined daily.

\section{The treatment of parasitised animals using plant extracts}

The potential antiparasitic effect of Indonesian plants $(P$. betle and $D$. sumatrana), was compared with the expected null effect of $A$. thaliana, as well as with the potentially positive effect of the Halocur oral solution (Intervet Production S.A., Rue de Lyons, France). Mice infected with $C$. proliferans two or three months before treatment with plant extracts were divided into groups (three animals per group) and treated with the following treatment doses administered per os. Treated non-infected and untreated infected and non-infected control groups were included in all experiments. The effect of administered extracts/drugs/ diluents on the course of parasitisation was evaluated as change in the parasitisation intensity expressed by OPG in comparison to parasitisation intensity of infected mice administered with only distilled water. The coefficient of determination $\left(\mathrm{r}^{2}\right)$ was calculated for each linear regression. All computation was carried out with the SigmaPlot 13.0 (Systat Software Inc., San Jose, CA). The histopathological changes of parasitised gastric mucosa were evaluated post mortem.

Trial 1. Groups of mice were treated daily for 14 days, beginning two months post inoculation with $C$. proliferans, with $12.5 \mathrm{mg}$ per $100 \mathrm{~g}$ of body mass (BM) of either P. betle, D. sumatrana or A. thaliana extracted in methanol, dissolved in DMSO, and diluted with sterile water to obtain a final concentration of $0.5 \%$ DMSO. The effect of the Halocur $(100 \mu \mathrm{g} / \mathrm{kg} \mathrm{BM})$ and the diluent $(0.5 \%$ DMSO in sterile water) was evaluated in infected control mice.

Trial 2. A second trial was conducted after the completion of the first trial. The treatments began three months post inoculation with $C$. proliferans. Three extraction media were used: methanol, methanol-THF and sterile water. Extracted material was dissolved in DMSO (except for that dissolved in sterile water) and diluted with sterile water to obtain a final concentration of $0.5 \%$ DMSO. A dose of $40 \mathrm{mg}$ of per $100 \mathrm{~g} \mathrm{BM}$ of either P. betle, D. sumatrana or $A$. thaliana extract was administered twice a day for 21 days. Additionally, the effect of the Halocur $(100 \mu \mathrm{g} / \mathrm{kg} \mathrm{BM})$ and the diluent $(0.5 \%$ DMSO in sterile water) was evaluated in infected control mice.

Parasitological dissection and tissue processing for microscopic evaluation

After either 14 (Trial 1) or 21 (Trial 2) days of treatment, control and treated animals were euthanised by cervical dislocation and dissected according to protocols described by Melicherová et al. (2014). For histological sectioning, gastric tissue was fixed in AFA (Alcohol-Formalin-Acetic Acid) solution and processed according to Valigurová et al. 2008. The blocks were cut using a Zeiss Hyrax M 300 rotary microtome and the $7 \mu$ m thick sections were stained with haematoxylin-eosin. Preparations were viewed using an Olympus BX61 microscope.

For scanning electron microscopy, samples of gastric tissue were fixed overnight at $4{ }^{\circ} \mathrm{C}$ in freshly prepared $2.5 \%$ glutaraldehyde $(\mathrm{v} / \mathrm{v})$ in cacodylate buffer $(0.1 \mathrm{M} ; \mathrm{pH} 7.4)$, washed $3 \times 15 \mathrm{~min}$ in the buffer, postfixed in $2 \% \mathrm{OsO}_{4}$ in cacodylate buffer for two hour at room temperature, and washed again $3 \times 15 \mathrm{~min}$ in buffer. After dehydration in a graded acetone series, specimens were critical point-dried using $\mathrm{CO}_{2}$, coated with gold, and examined using a JEOL JSM-7401F - Field Emission Scanning Microscope. Abbreviations used in Figs. 1-9: LM - light microscopy; SEM - scanning electron microscopy

\section{RESULTS}

\section{Histopathological observations of the gastric tissue of uninfected and infected rodents}

In the stomach of healthy (control) Mastomys coucha individuals, the surface of the gastric mucosa was smooth with a brain-like ornamentation (Fig. 1A). In histological sections stained with haematoxylin-eosin, the gastric mucosa, along with a thin layer of muscularis mucosae and subjacent submucosa, appeared homogeneously pink with well-demarcated blue nuclei (Fig. 1B). It was 

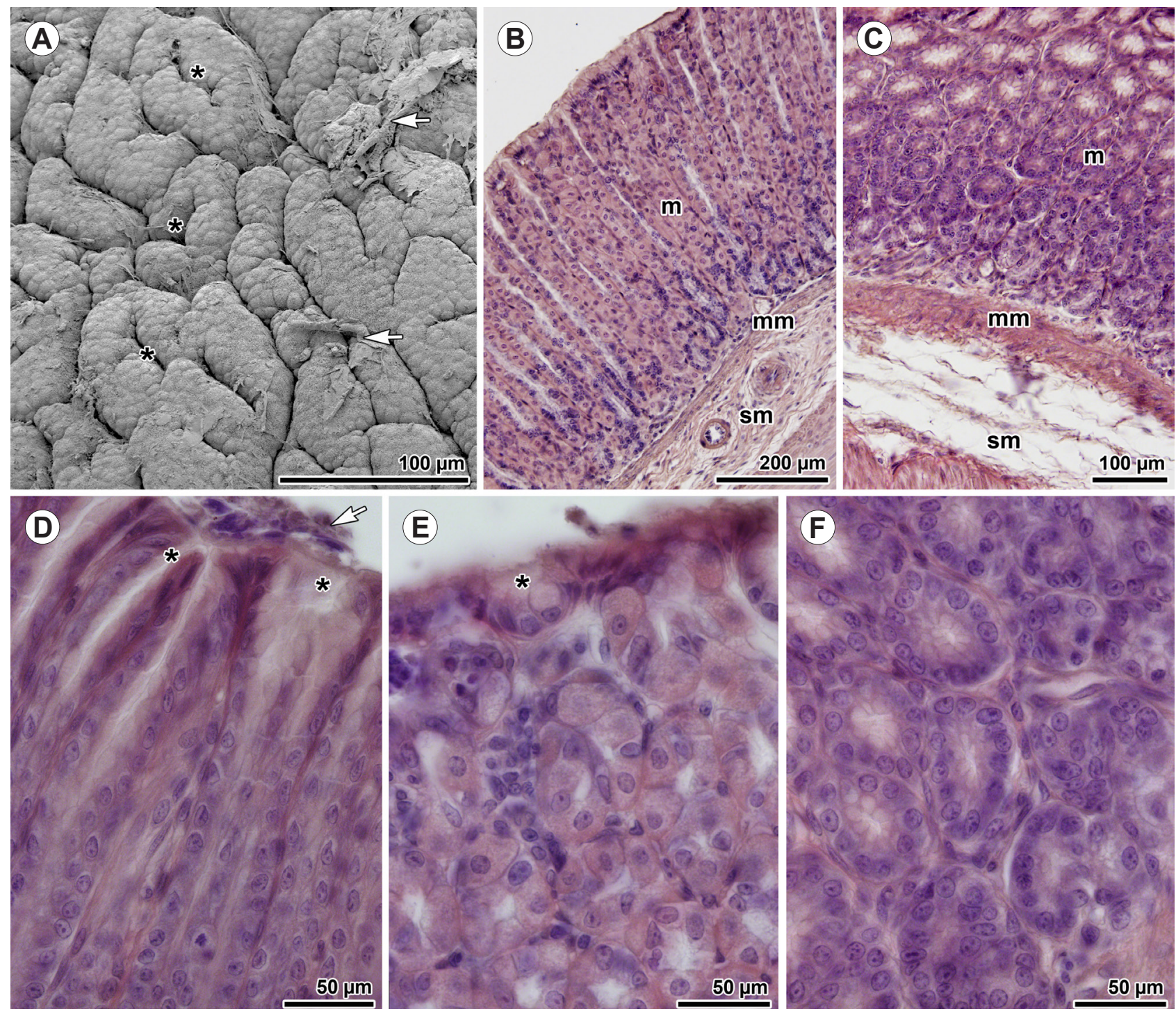

Fig. 1. Healthy gastric mucosa of Mastomys coucha (Smith). A - general view of surface of the gastric mucosa exhibiting constricted gastric pits; note the remnants of mucus not washed away during rinsing (SEM); $\mathbf{B}$ - general view of gastric mucosa showing the longitudinally sectioned pits and glands (LM); C - general view of mucosa with cross-sectioned gastric glands (LM, histology); D - detailed view of constricted gastric pits in longitudinal section (LM, histology); $\mathbf{E}$ - detailed view of constricted pits in cross section (LM, histology); $\mathbf{F}$ - detailed view of constricted glands in cross sections (LM, histology); asterisk - gastric pit; $\mathrm{m}$ - mucosa; mm - muscularis mucosae; sm - submucosa; white arrow - mucus with cell debris.

possible to distinguish quite easily the tubular glands and necks ended by pits invaginating the luminal surface of mucosa (Fig. 1B,C). The gastric pits and glands were obviously constricted and contained within a thin lamina propria (Fig. 1A-F). A tall simple columnar epithelium lined the mucosal surface and gastric pits (Fig. 1B). Surface mucous cells lining the pits as well as mucous neck cells demarcating the necks of gastric glands appeared pale (Fig. 1B), while the cells forming the base of glands were stained darker with prominent, intensively stained nuclei (Fig. 1C,F).

In mice infected with Cryptosporidium proliferans, parasite endogenous stages were restricted to the epithelial cells in the glandular part of the gastric mucosa. This species primarily parasitises epithelial cells lining the gastric pits and glands, though some parasites could be found attached to cells lining the luminal surface of the gastric epi- thelium, especially as parasitisation progressed (most likely due to the increased space requirements). The duration of the prepatent period (18-21 days) and the chronology of pathological changes correspond to previously published data (Melicherová et al. 2014).

In the first trial, the use of mice in a relatively early stage of cryptosporidiosis (two months post inoculation with $C$. proliferans) was shown to be unsuitable for the microscopic evaluation of treatment effects, as affected gastric mucosa exhibited only mild to moderate pathological changes. The gastric tissue was also irregularly affected by cryptosporidia in an island-like manner, where individual parasitised gastric pits were surrounded by regions of healthy epithelium. The affected gastric tissue showed no obvious alterations and the pits appeared almost fully constricted when evaluated under SEM (Fig. 2A). Despite the mild character of pathological alterations visible by SEM, 

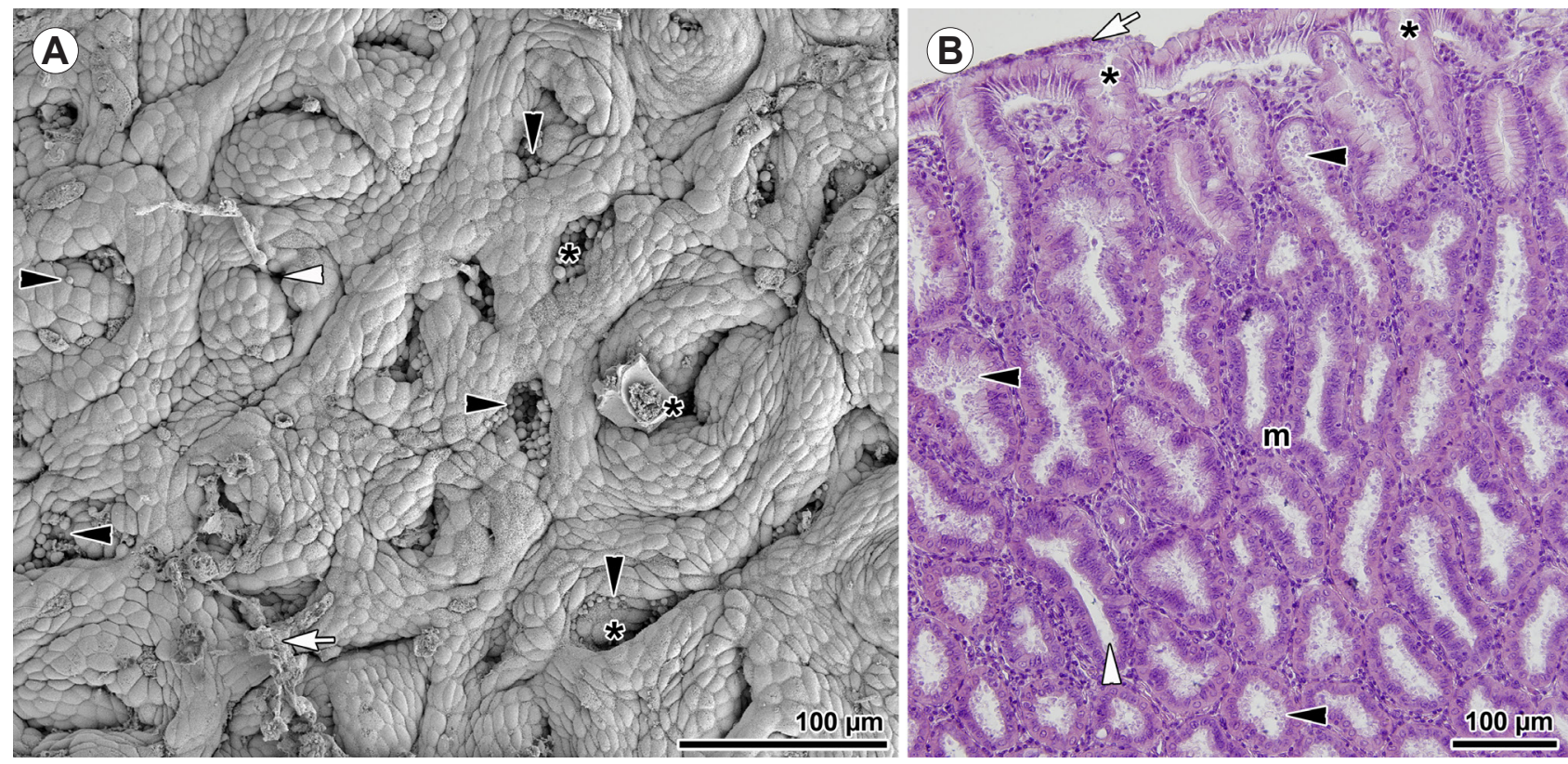

Fig. 2. Pathological alterations to gastric mucosa induced by Cryptosporidium proliferans Kváč, Havrdová, Hlásková, Daňková, Kanděra, Ježková, Vítovec, Sak, Ortega, Xiao, Modrý, Chelladurai, Prantlová et McEvoy, 2016 in control Mastomys coucha (Smith) from Trial 1. A - superficial view of surface of the gastric mucosa exhibiting slightly enlarged gastric pits (SEM); $\mathbf{B}$ - general view of the gastric mucosa with longitudinally sectioned pits. The gastric pits and glands exhibit moderate dilation when viewed in tangential and cross sections (LM, histology); asterisk - gastric pit, black arrowhead - cryptosporidia, $\mathrm{m}$ - mucosa, white arrow - mucus with cell debris, white arrowhead - cryptosporidia-free pit/gland.

histological sectioning revealed the moderate dilatation of gastric glands due to the presence of numerous cryptosporidia (Fig. 2B).

Pathological changes in affected gastric tissue became more prominent three months post inoculation with C. proliferans, when the parasitisation entered a chronic phase (Fig. 3A-I). Such mice, used in Trial 2, had the surface of their gastric glandular epithelium markedly deformed due to intense pathological changes. At the macroscopic level, the gastric mucosa was typified by a cauliflower-like appearance. The epithelium proliferated into the luminal space, so that the stomach exhibited extensive folding that was especially visible under SEM (Fig. 3A,C,D). This was the result of an increase in the volume of the lamina propria, which then increased the distance between individual gastric glands and caused the longitudinal folds to become twisted and obviously deformed. The progress of parasitisation caused a distinctive form of diffuse mucosal hypertrophy typified by the presence of enlarged/giant gastric folds and intensive epithelial hyperplasia.

The gastric glands, packed with various developmental stages of C. proliferans and necrotic material, were markedly dilated and hypertrophied (Fig. 3B,E-I). In addition, numerous cryptosporidia developed attached to the luminal surface of the gastric mucosa outside the dilated pits (Fig. 3D). The affected glands, lined with many undifferentiated cells, lost their normal architecture; the atrophic epithelial cells of the affected glands exhibited cuboidal or squamous metaplasia (Fig. 3G-I). Besides the more intense staining of affected tissue in histological sections, another feature typical of advanced cryptosporidiosis was the thickening of muscularis mucosae (Fig. 3B). Parasitised tissue ex- hibited various degrees of oedema and the infiltration of the lamina propria and submucosa with neutrophils (Fig. 3B,E). Stomach weight (due to proliferating mucosa) and epithelial height were considerably greater than in non-infected animals. Interestingly, despite the chronicity of infection, no clinical signs were observed in infected rodents.

\section{Treatment with plant extracts and Halocur}

Trial 1 served as the primary screening of experimental protocols and the selected treatment doses based on related literature and empirical data on other unicellular parasites used in our research (Pecková et al. 2018). On the basis of the results obtained with daily doses of $12.5 \mathrm{mg} / 100 \mathrm{~g} \mathrm{BM}$ applied for 14 consecutive days, we decided to increase the treatment doses to $40 \mathrm{mg}$ per $100 \mathrm{~g} \mathrm{BM}$ administered twice daily for 21 consecutive days in Trial 2. Furthermore, in Trial 2, we tested and compared the efficacy of selected plant extracts obtained using various solvent media methanol, methanol-THF, and sterile water. In both trials, an oral administration containing $100 \mu \mathrm{g} / \mathrm{kg}$ BM halofuginone lactate (Halocur), a salt whose antiprotozoal properties and efficacy against Cryptosporidium parvum have been demonstrated under in vitro and in vivo conditions (Giadinis et al. 2008, Petermann et al. 2014), was used as a control treatment.

One of the parameters used to evaluate parasitisation intensity was the monitoring of the number of shed oocysts detected in faeces. Generally, the variations in oocyst shedding were comparable in all experimental groups treated with either plant extracts or Halocur. A decline in oocyst number in Trial 1 can be observed in groups treated for 14 days with Diospyros sumatrana extracted by metha- 

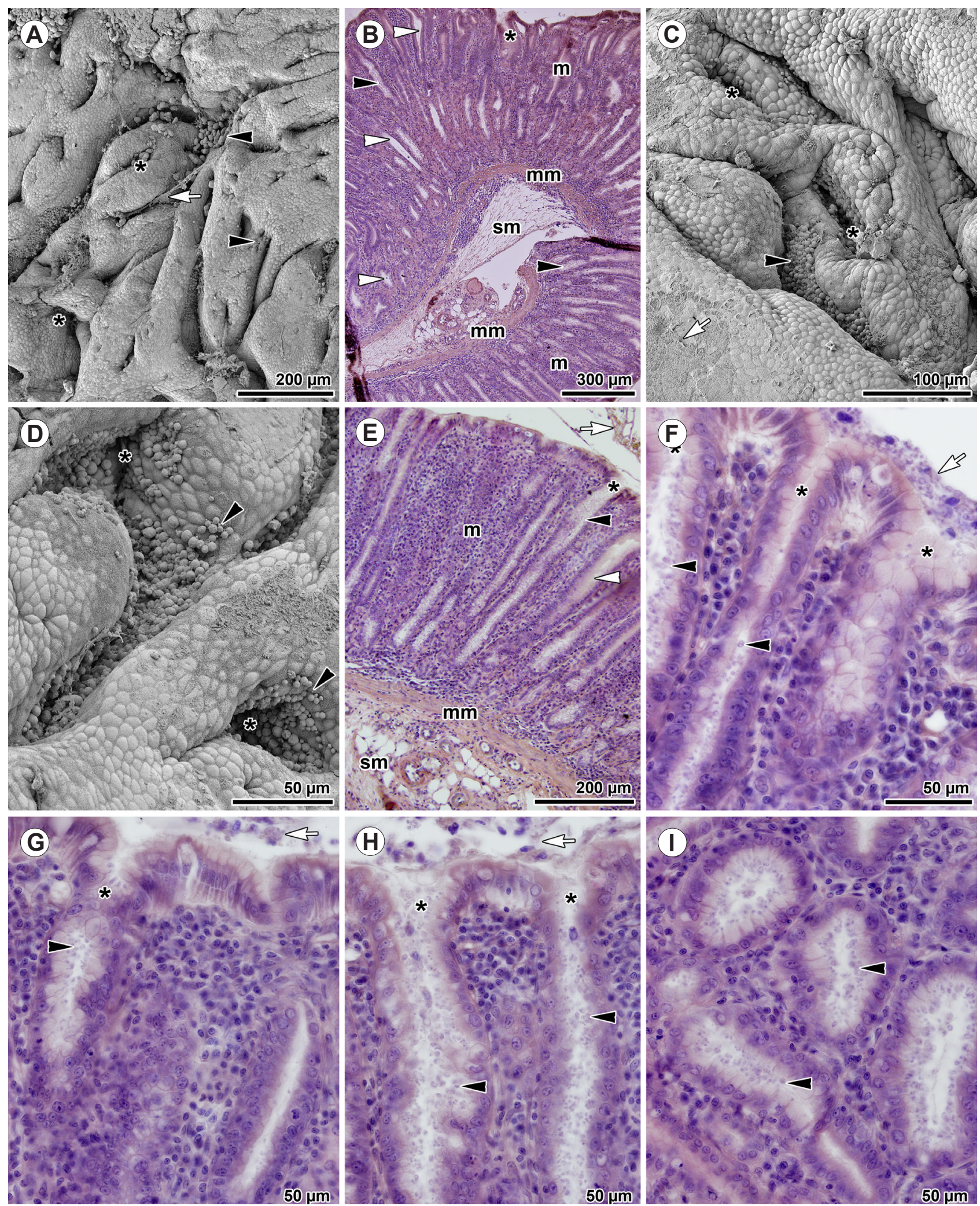

Fig. 3. Pathological alterations to gastric mucosa induced by Cryptosporidium proliferans Kváč, Havrdová, Hlásková, Daňková, Kanděra, Ježková, Vítovec, Sak, Ortega, Xiao, Modrý, Chelladurai, Prantlová et McEvoy, 2016 in control Mastomys coucha (Smith) from Trial 2. A - superficial view of the gastric mucosa exhibiting extensive folding and intense parasitisation (SEM); $\mathbf{B}-$ general view of the gastric mucosa and submucosa in longitudinal section (LM, histology); C, D - detailed view of dilated pits filled with numerous parasites (SEM); $\mathbf{E}$ - gastric mucosa showing the longitudinally sectioned pits and glands (LM, histology); $\mathbf{F}-\mathbf{H}-$ detailed view of parasitised pits and glands in longitudinal section (LM, histology); I - detailed view of cross-sectioned gastric glands filled with parasites (LM, histology); asterisk - gastric pit; black arrowhead - cryptosporidia; $\mathrm{m}$ - mucosa; mm - muscularis mucosae; sm submucosa; white arrow - mucus with cell debris; white arrowhead - cryptosporidia-free pit/gland. 


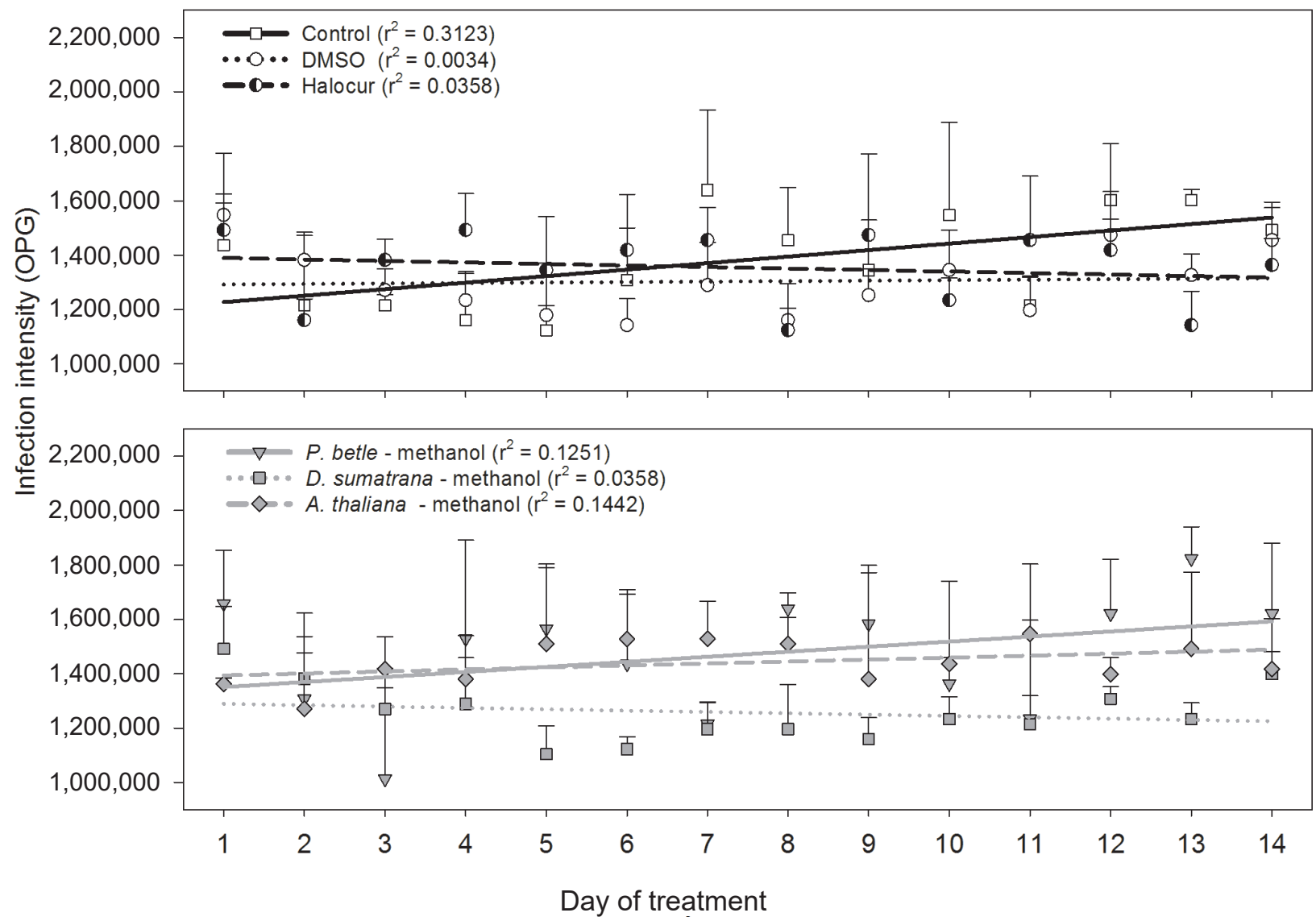

Fig. 4. Infection dynamics of Cryptosporidium proliferans Kváč, Havrdová, Hlásková, Daňková, Kanděra, Ježková, Vítovec, Sak, Ortega, Xiao, Modrý, Chelladurai, Prantlová et McEvoy, 2016 in Trial 1. Groups of eight-week-old Mastomys coucha (Smith) inoculated with a dose of 106 oocysts two months before treatment and subsequently treated daily for 14 days with $12.5 \mathrm{mg}$ per $100 \mathrm{~g}$ of body mass of either Piper betle, Diospyros sumatrana or Arabidopsis thaliana extracted in methanol. The linear regression including regression coefficient is included for each experimental group.

nol and Halocur (Fig. 4). In contrast, non-treated controls, controls treated with pure DMSO and animals treated with Piper betle and Arabidopsis thaliana extracted by methanol exhibited an increase in oocyst shedding (Fig. 4). In Trial 2, a decline in oocyst shedding occurred in groups treated for 21 days with $A$. thaliana by methanol-THF, $D$. sumatrana by methanol-THF and Halocur (Fig. 5). An increase occurred in non-treated controls and animals treated with pure DMSO, $P$. betle extracted by methanol, $P$. betle by methanol-THF, $P$. betle by sterile water, $A$. thaliana by methanol $A$. thaliana by sterile water, $D$. sumatrana by methanol, and D. sumatrana by sterile water (Fig. 5). The coefficient of determination, however, was low in all experimental groups, with the exception of non-treated controls and controls treated with pure DMSO in Trial 2 (Fig. 5).

Despite an obvious decrease in oocyst shedding in some animals, post mortem histological examinations at the end of both trials revealed heavy cryptosporidiosis in all non-treated (Figs. 1-3) and treated animals (Figs. 6-9). Only histological sections from animals treated for 21 days (Trial 2) are shown to demonstrate the status of parasitised gastric tissue at the end of the trial. Histopathological data show that, independently of the solvent medium used, extracts from $P$. betle (Fig. 6A-I) and D. sumatrana (Fig.
7A-I) neither helped to eradicate the parasites nor cured the pathological changes induced by $C$. proliferans. When compared to non-treated controls (Fig. 3A-I), no significant difference was observed in parasitisation intensity or in associated pathological alterations to the gastric mucosa in treated animals examined in SEM or histological preparations.

Surprisingly, the application of a control with no expected effect, the extract of $A$. thaliana (Fig. 8A-I), seemed to have a positive impact on parasitised gastric mucosa, especially when dissolved in methanol-THF (Fig. 8G-I). This was obvious especially in SEM preparations, where the pathological folding of parasitised gastric tissue appeared less intense (Fig. 8G) when compared to those in non-treated animals (Fig. 3A,C,D) and the effects of other treatments (Figs. 7A,D,G, and 8A,D). Some degree of this effect of $A$. thaliana on parasitised gastric mucosa was also visible in histological sections; i.e. the architecture of the gastric glands was closer to the normal state and the epithelial cells lining the gastric glands were slightly less atrophic (Fig. 8I).

Although it slightly decreased oocyst excretion, even prolonged treatment with Halocur was insufficiently effective in treating gastric cryptosporidiosis (Fig. 9A-C). The 

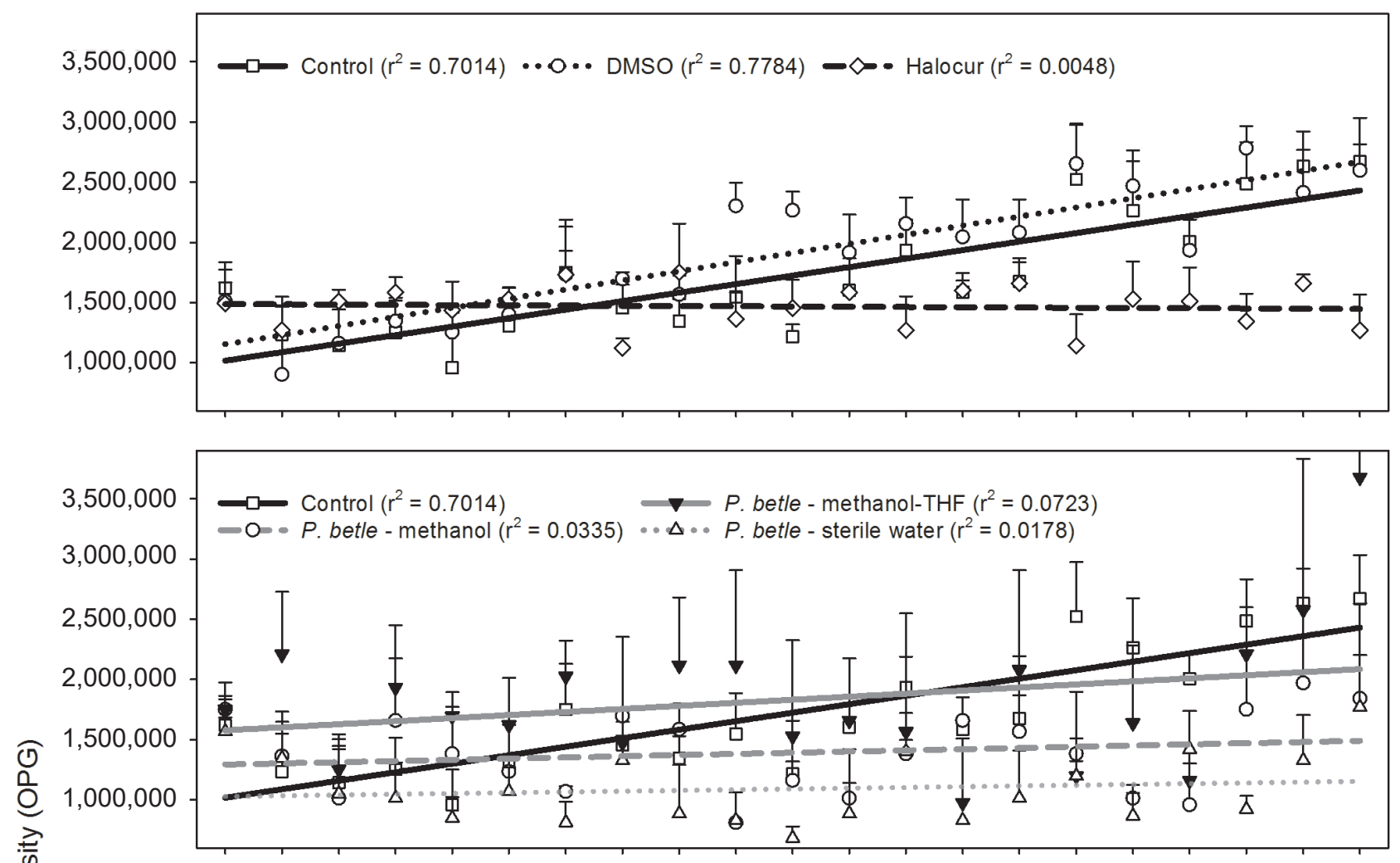

过
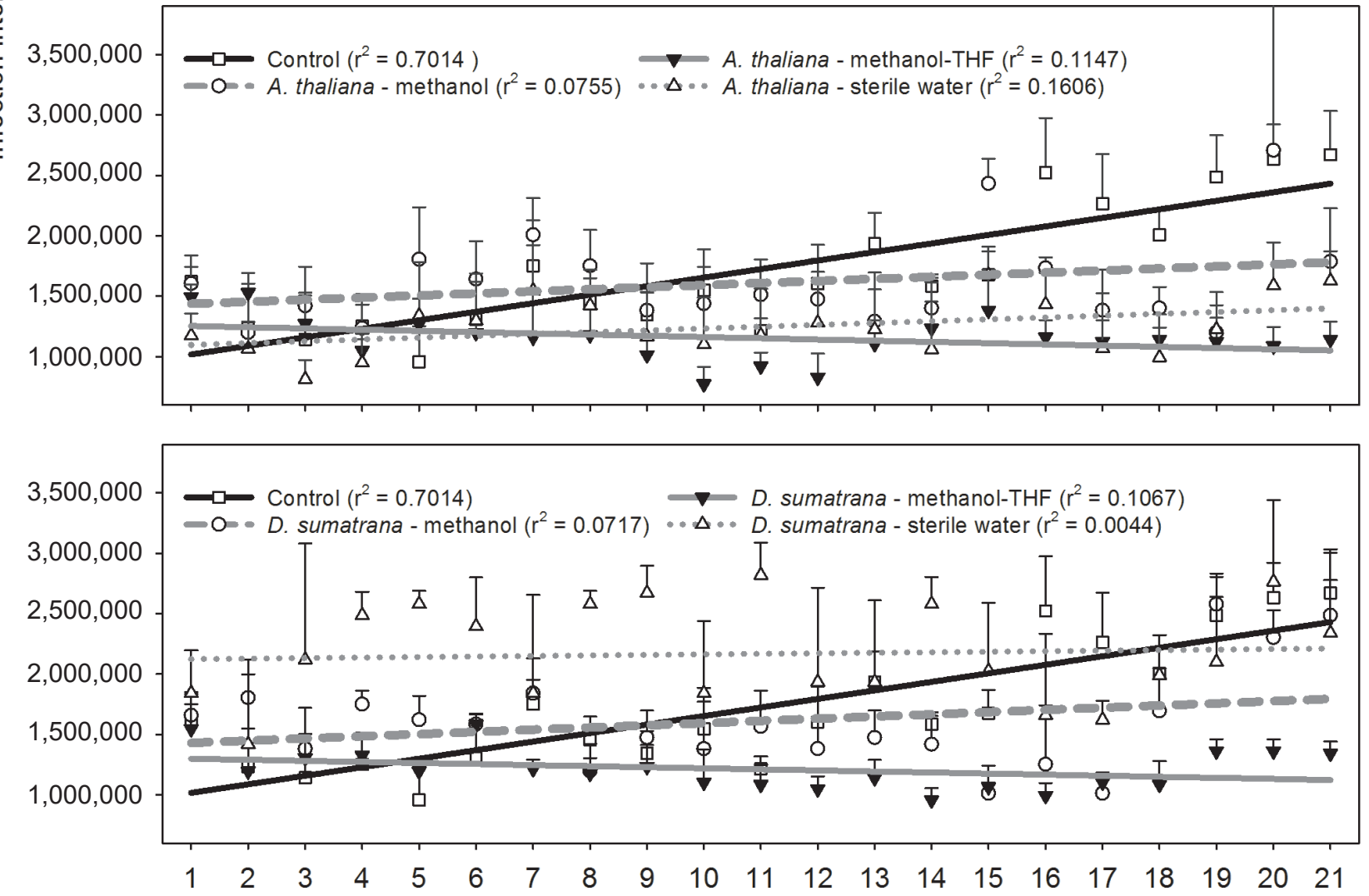

Day of treatment

Fig. 5. Infection dynamics of Cryptosporidium proliferans Kváč, Havrdová, Hlásková, Daňková, Kanděra, Ježková, Vítovec, Sak, Ortega, Xiao, Modrý, Chelladurai, Prantlová et McEvoy, 2016 in Trial 2. Groups of eight-week-old Mastomys coucha (Smith) inoculated with a dose of 106 oocysts three months previously were treated twice a day for 21 days with a dose of $40.0 \mathrm{mg}$ per $100 \mathrm{~g}$ of body mass of either Piper betle, Diospyros sumatrana or Arabidopsis thaliana extracted in methanol, ethanol-tetrahydrofuran (methanol-THF) or sterile water. The linear regression including regression coefficient is included for each experimental group. 

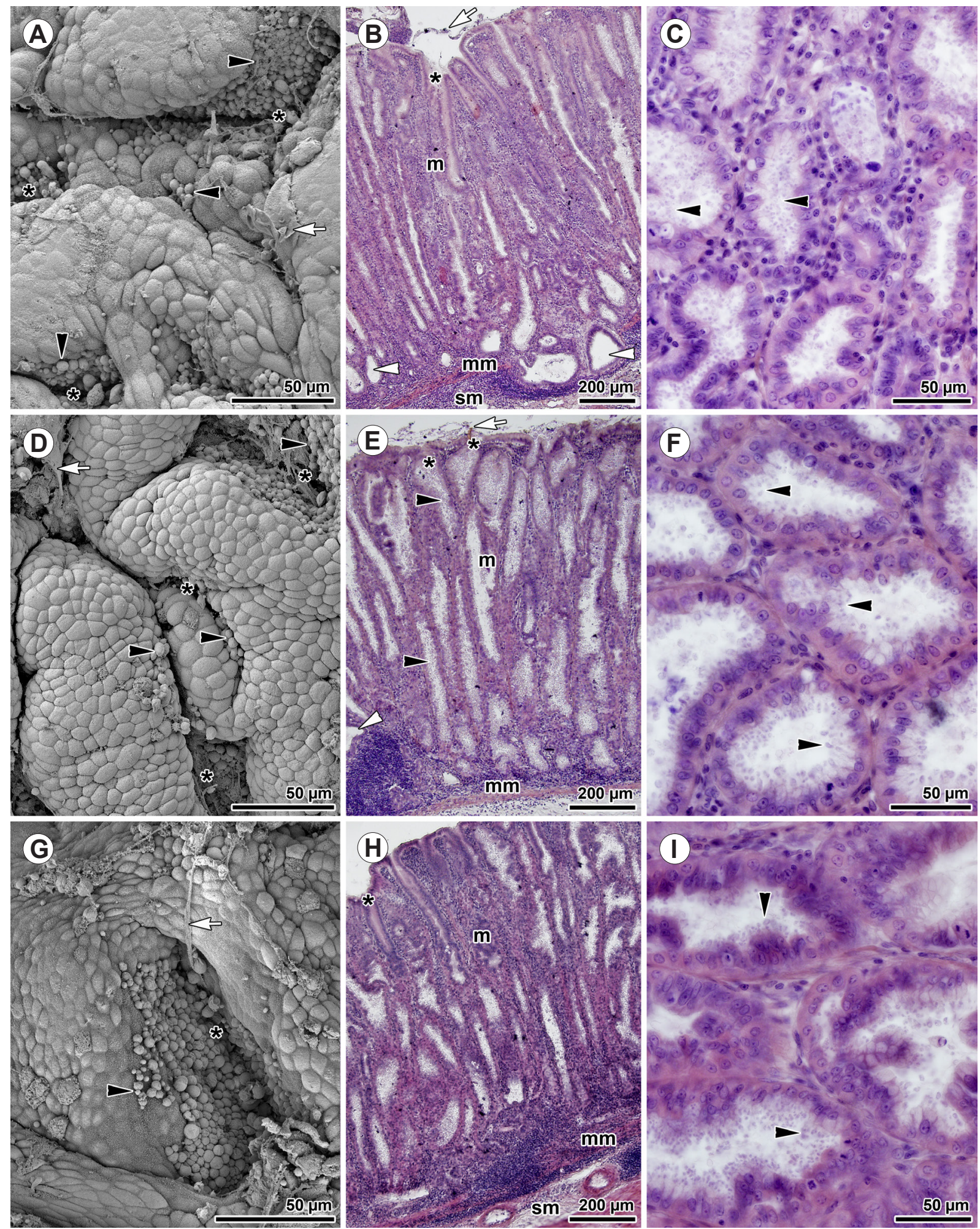

Fig. 6. The effect of Piper betle extract on Mastomys coucha (Smith) gastric mucosa parasitised with Cryptosporidium proliferans Kváč, Havrdová, Hlásková, Daňková, Kanděra, Ježková, Vítovec, Sak, Ortega, Xiao, Modrý, Chelladurai, Prantlová et McEvoy, 2016 in Trial 2. A-C - P. betle in sterile water: $\mathbf{A}$ - superficial view of the gastric mucosa (SEM); $\mathbf{B}$ - general view of the gastric mucosa in longitudinal section (LM, histology); C - detailed view of cross-sectioned glands filled with parasites (LM, histology); D-F - P. betle in methanol: D - superficial view of the gastric mucosa (SEM); $\mathbf{E}$ - general view of the gastric mucosa in longitudinal section (LM, histology); $\mathbf{F}$ - detailed view of cross-sectioned glands filled with parasites (LM, histology); G-I - P. betle in methanol-THF: $\mathbf{G}-$ superficial view of the gastric mucosa (SEM); $\mathbf{H}$ - general view of the gastric mucosa and submucosa in longitudinal section (LM, histology); I - detailed view of cross-sectioned glands filled with parasites (LM, histology); asterisk - gastric pit; black arrowhead - cryptosporidia; $\mathrm{m}$ - mucosa; $\mathrm{mm}$ - muscularis mucosae; sm - submucosa; white arrow - mucus with cell debris; white arrowhead cryptosporidia-free pit/gland. 

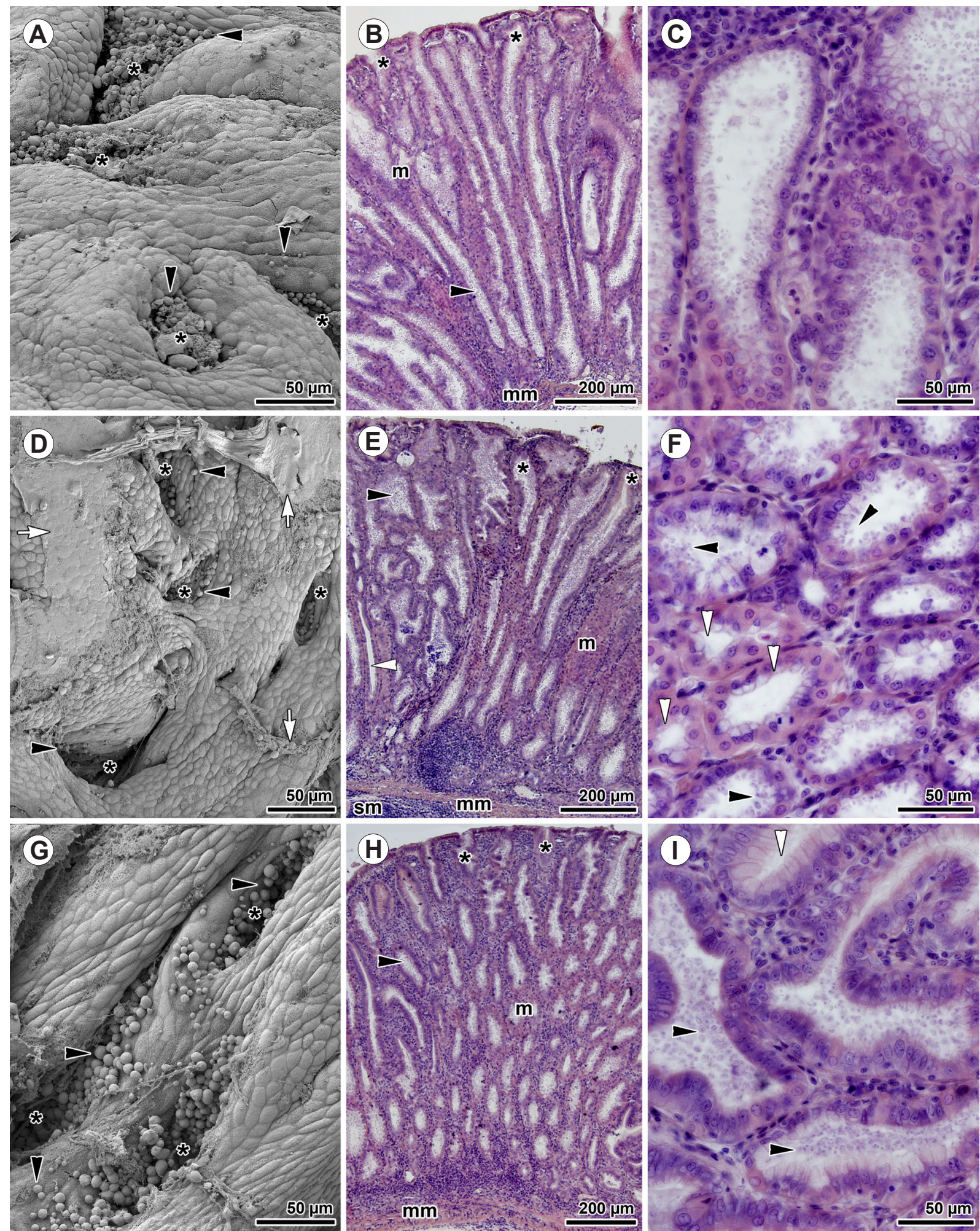

Fig. 7. The effect of Diospyros sumatrana extract on Mastomys coucha (Smith) gastric mucosa parasitised with Cryptosporidium proliferans Kváč, Havrdová, Hlásková, Daňková, Kanděra, Ježková, Vítovec, Sak, Ortega, Xiao, Modrý, Chelladurai, Prantlová et McEvoy, 2016 in Trial 2. A-C - D. sumatrana in sterile water: A - superficial view of the gastric mucosa (SEM); $\mathbf{B}$ - general view of the gastric mucosa in longitudinal section (LM, histology); $\mathbf{C}$ - detailed view of tangentially-sectioned glands filled with parasites (LM, histology); D-F - D. sumatrana in methanol: D - superficial view of the gastric mucosa (SEM); $\mathbf{E}$ - general view of the gastric mucosa in longitudinal section (LM, histology); F - detailed view of cross-sectioned glands filled with parasites and neighbouring empty glands (LM, histology); G-I - D. sumatrana in methanol-THF: $\mathbf{G}$ - superficial view of the gastric mucosa (SEM); $\mathbf{H}$ - general view of the gastric mucosa in longitudinal section (LM, histology); I - detailed view of tangentially-sectioned glands filled with parasites (LM, histology); asterisk - gastric pit, black arrowhead - cryptosporidia; $\mathrm{m}$ - mucosa; mm - muscularis mucosae; sm - submucosa; white arrow - mucus with cell debris; white arrowhead - cryptosporidia-free pit/gland. 

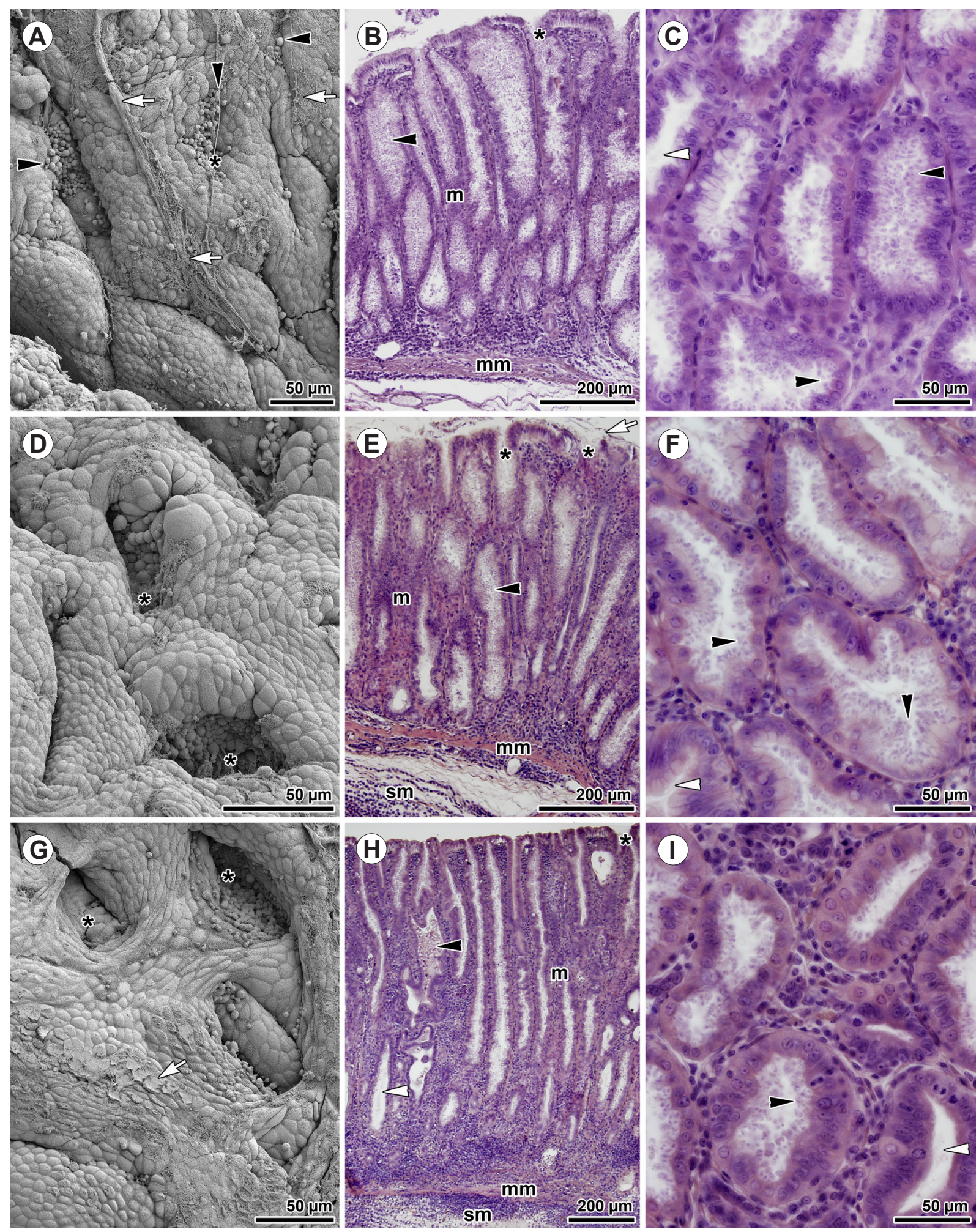

Fig. 8. The effect of Arabidopsis thaliana extract on Mastomys coucha (Smith) gastric mucosa parasitised with Cryptosporidium proliferans Kváč, Havrdová, Hlásková, Daňková, Kanděra, Ježková, Vítovec, Sak, Ortega, Xiao, Modrý, Chelladurai, Prantlová et McEvoy, 2016 in Trial 2. A-C - A. thaliana in sterile water: A - superficial view of the gastric mucosa (SEM); $\mathbf{B}-$ general view of the gastric mucosa in longitudinal section (LM, histology); $\mathbf{C}$ - detailed view of cross-sectioned glands filled with parasites (LM, histology); D-F - A. thaliana in methanol: $\mathbf{D}$ - superficial view of the gastric mucosa (SEM); $\mathbf{E}$ - general view of the gastric mucosa in longitudinal section (LM, histology); F - detailed view of cross-sectioned glands filled with parasites (LM, histology); G-I - $A$. thaliana in methanol-THF: $\mathbf{G}$ - superficial view of the gastric mucosa (SEM); H - general view of the gastric mucosa in longitudinal section (LM, histology); I - detailed view of cross-sectioned glands filled with parasites (LM, histology); asterisk - gastric pit; black arrowhead - cryptosporidia; $\mathrm{m}$ - mucosa; $\mathrm{mm}$ - muscularis mucosae; $\mathrm{sm}$ - submucosa; white arrow - mucus with cell debris; white arrowhead - cryptosporidia-free pit/gland. 

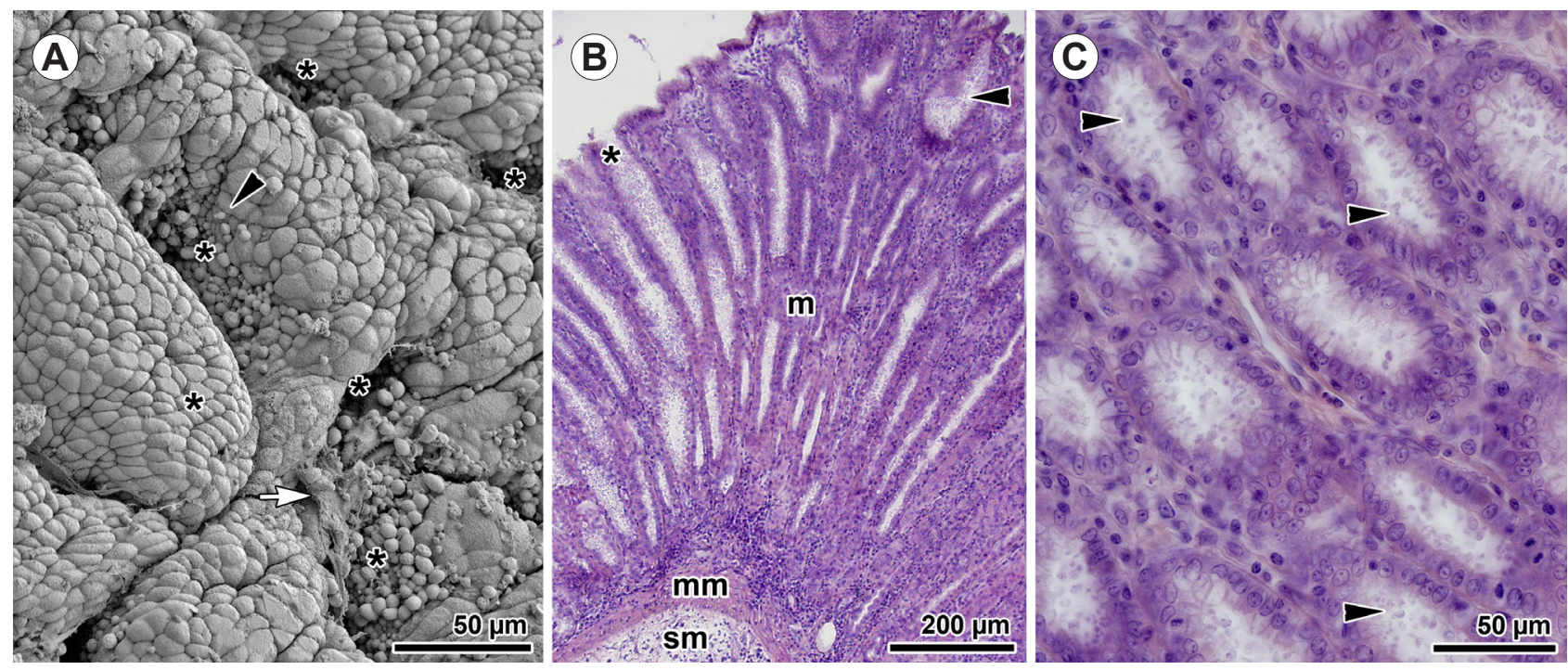

Fig. 9. The effect of Halocur on Mastomys coucha (Smith) gastric mucosa parasitised with Cryptosporidium proliferans Kváč, Havrdová, Hlásková, Daňková, Kanděra, Ježková, Vítovec, Sak, Ortega, Xiao, Modrý, Chelladurai, Prantlová et McEvoy, 2016 in Trial 2. A - superficial view of the gastric mucosa, halocur in PBS (SEM); B - general view of the gastric mucosa in longitudinal section, halocur in PBS (LM, histology); C - detailed view of cross-sectioned glands filled with parasites, halocur in PBS (LM, histology); asterisk - gastric pit, black arrowhead - cryptosporidia, $\mathrm{m}$ - mucosa, $\mathrm{mm}$ - muscularis mucosae, $\mathrm{sm}$ - submucosa, white arrow - mucus with cell debris, white arrowhead - cryptosporidia-free pit/gland.

generally recommended dose for intestinal cryptosporidiosis, corresponding to $100 \mu \mathrm{g} / \mathrm{kg} \mathrm{BM}$ of halofuginone administered for seven consecutive days, was reported to be effective in the past (Giadinis et al. 2008, Petermann et al. 2014). In our study, the period of Halocur administration was extended to 14 (Trial 1) and 21 days (Trial 2). Treated animals showed no symptoms of toxicity (no clinical signs of overdosing). However, SEM observations of the intensively folded surface of the gastric mucosa, with the presence of various developmental stages of $C$. proliferans, confirmed heavy infection (Fig. 9A). Histopathological changes (Fig. 9A-C) were very similar to those found in untreated individuals (Fig. 3A-I). The only difference, noticeable at higher magnification, was the better preservation of epithelial cells lining the glands (Fig. 9C). These cells appeared less atrophic with more preserved nuclei compared to non-treated animals or those treated with $P$. betle and D. sumatrana.

\section{DISCUSSION}

\section{Histopathological changes related to gastric cryptosporidiosis}

Studies on animal gastric cryptosporidiosis usually report only mild histopathological changes represented by the dilatation and epithelial metaplasia of gastric glands. These are generally reported without obvious alterations to host health status, and with no or only insignificant inflammatory responses in the lamina propria, although inflammatory infiltrates are occasionally seen (e.g. Taylor et al. 1999, Masuno et al. 2006, Kváč et al. 2008). Nevertheless, there are obvious differences in histopathological changes induced by different gastric species, load of parasite inoculum or immunological status of their host.
In addition, other pathogens might escalate the impact of cryptosporidiosis on host tissue. For example, in mice simultaneously infected with Cryptosporidium muris and Helicobacter felis, the gastric glands were more severely parasitised by cryptosporidia, and their stomachs showed more severe cellular infiltrates (Tatar et al. 1995). The fundus glands of nude mice inoculated with strain RN 66 of C. muris showed dilatation with mild epithelial changes (Taylor et al. 1999), and only mice receiving an inoculum of 1,000,000 oocysts showed an inflammatory reaction.

A study using SCID mice reported only mild gastric cryptosporidiosis without gross pathologic findings (Jalovecká et al. 2010). The maximum peak of parasitisation intensity was $21 \mathrm{DPI}$, whereas the highest numbers of immune cells occurred in the gastric epithelium at 28 DPI, a period when the majority of mice had already been cured of the infection. Immunocompetent mice inoculated with either C. muris $\mathrm{CB} 03$ or Cryptosporidium proliferans developed $\mathrm{T}$ cell responses leading to a clearance of the primary infection and complete resistance to re-infection with the same strain (Jalovecká et al. 2010, Kváč et al. 2011). In contrast, the intensity of infection with $C$. proliferans in experimentally infected Mastomys coucha continued to increase throughout experiments with maximum oocysts' shedding at 126 DPI and animals developed lifelong (chronic) infection (Melicherová et al. 2014, Kváč et al. 2016).

Despite the considerable gross pathology of gastric epithelium documented in this and previous studies (Melicherová et al. 2014, Kváč et al. 2016), neither clinical signs of cryptosporidiosis, nor weight lost were observed in southern multimammate mice. In contrast to previous studies (Melicherová et al. 2014, Kváč et al. 2016), we observed the inflammatory infiltration of muscularis mucosae 
and submucosa with neutrophils. Great variations in oocyst shedding accompanied by heavy cryptosporidiosis revealed in histological sections of southern multimammate mice stomach in this study are also rather inconsistent with the recent study by Kváč et al. (2016), in which high numbers of cryptosporidian developmental stages were typically associated with high oocyst shedding.

In cattle parasitised by Cryptosporidium andersoni, despite the lack of apparent clinical signs, severe infection was observed in the abomasum with prominent hyperplasia of mucosa, along with a moderate degree of inflammatory infiltration of lamina propria (Masuno et al. 2006). The number and length of gastric pits increased considerably because of the increasing number of epithelial cells. Thickening and granulation of abomasal mucosa were often reported (Anderson 1998). The epithelium of the stomach antrum in an immunocompetent human patient with isolated gastric cryptosporidiosis was shown to be disorganised, fragile, and infiltrated by neutrophils (Ramsay et al. 2007). Gastric involvement in AIDS patients is usually considered to be secondary to retrograde spread from the small intestine (Val-Bernal et al. 2013). Related to Cryptosporidium gastropathy, patients suffer from vomiting and epigastric pain. The gastric wall might exhibit a lack of distensibility, stiffness, thickening, distortion or erosions of the mucosal folds involving the antrum region (Val-Bernal et al. 2013). Regularly in the same biopsy, areas with cryptosporidia were contiguous to negative ones. Various degrees of mucosal alterations were observed, even in the same individual. Besides hyperplastic reactive changes, high intensity of infection correlates with erosions and acute inflammation. Commonly, individuals with gastric cryptosporidiosis show no significant endoscopic alteration to the gastric mucosa, even though histological features are highly modified. In this and previous studies (Melicherová et al. 2014), we also observed a patchy (island-like) distribution of $C$. proliferans. Similarly to the course of cryptosporidiosis in other homoiotherm vertebrates, the rodents in our study did not show any clinical signs of cryptosporidiosis.

\section{Trends in drug development and screening studies testing potentially anti- cryptosporidial compounds}

Cryptosporidium spp. represent a highly problematic target for drug development. One of the self-protective strategies of cryptosporidia against the harsh conditions of the host's gastrointestinal tract is their unique epicellular localisation within a parasitophorous sac of host cell origin (Valigurová et al. 2007, 2008). The oocysts of cryptosporidia sporulate inside the host and infective oocysts are transmitted by the faecal-oral route. Besides the most commonly used antibiotics and halofuginone, numerous compounds have been screened for potential anti-cryptosporidial activity, but the majority were ineffective. Although some drugs have shown promise in calves and lambs, they are too expensive (paramomycin) or highly toxic at effective doses (halfuginone lactate and lasalocid) (Tzipori 1998). Therefore, along with antibiotics administered to control secondary bacterial infections, it has been recommended to treat intestinal cryptosporidiosis in calves with fluid therapy and the correction of acid-base disturbances (Tzipori 1998). Colostrum containing anti-Cryptosporidium antibodies also appears to be beneficial (O’Donoghue 1995).

More recent studies have reported halofuginone (Halocur) administration at the recommended dose of $100 \mu \mathrm{g} / \mathrm{kg}$ for $7-10$ consecutive days as very effective in stopping diarrhoea and preventing deaths without side effects (Giadinis et al. 2008, Petermann et al. 2014). At this dose, it appears to inhibit the reproduction of cryptosporidia within the host and encourages the development of immunity in lambs (Causapé et al. 1999). Nitazoxanide, though not effective in immunocompromised patients, significantly shortens the duration of diarrhoea and decreases mortality in adults and malnourished children (Gargala 2008).

Similarly, newly synthesised nitro- or non nitro- thiazolide compounds, derived from nitazoxanide, have been shown to be effective against Cryptosporidium parvum (see Gargala 2008). Furthermore, compounds active against protein disulphide isomerases (PDI2 and PDI4), the epidermal growth factor (EGF) receptor, pp60v-src, and pp110gag-fes, as well as new isoflavone derivatives, seem to represent promising targets (Ortega-Pierres et al. 2009). SCID mice orally administered with the chicken egg yolk antibody against $C$. parvum infection demonstrated partial reduction in oocyst shedding (Kobayashi et al. 2004).

Whilst the majority of these studies have been performed on intestinal cryptosporidia, usually C. parvum, there is still a lack of experimental work dealing with the treatment of gastric cryptosporidiosis and most of the few published works deal with the treatment of AIDS patients. One of these papers has shown a positive effect of paramomycin on reducing inflammation of the gastric mucosa and mild relief from pain and diarrhoea, despite parasite persistence in mucosa (Ventura et al. 1997). Another study reported the eradication of AIDS-related gastric cryptosporidiosis with azithromycin and suggested long-term treatment (Díaz Peromingo et al. 1999).

In our study, none of the Indonesian plant extracts were shown to be effective against gastric cryptosporidiosis, despite their proven activity against other protists parasitising the small intestine (Pecková et al. 2018). For the first trial, the dosage was calculated based on behavioural observation of self-medication of wild animals (e.g. the number of plant leaves consumed), but the dosage for the second trial was increased to $40 \mathrm{mg}$ to increase the potential antiparasitic effect. This dosage was calculated based on maximum concentrations of extracts reported in the literature (e.g. Bin-Hafeez et al. 2003, Squires et al. 2011). Although additional assays with different doses in a wide scale would be of interest, such an extensive experiment would be too demanding of time and material, especially in the number of laboratory rodents required. Hence, respecting the rules for breeding animals, regulated by Czech legislation and the legislation of the European Commission on protection of animals against cruelty, we have designed our experiments so that we do not use too many laboratory rodents unnecessarily, as do most of the world's laboratories. 
The oral administration of Halocur - even for a prolonged period - was not sufficiently effective either, though it slightly decreased the degree of oocyst shedding and seemed to facilitate the regeneration of epithelial cells lining the gastric pits. Nevertheless, in contrast to previous reports, it did not seem to inhibit the reproduction of cryptosporidia, although some slight decrease might be observed in the trendline showing oocyst excretion (Figs. 4, 5). Similarly, halofuginone treatment did not produce a satisfactory therapeutic outcome for infection with Cryptosporidium serpentis Levine, 1980 affecting the gastric mucosa of snakes (Graczyk et al. 1996), suggesting its ineffectiveness against gastric cryptosporidiosis.

Of special interest, however, was the positive impact of Arabidopsis thaliana on the gastric mucosa pathologically altered by chronic cryptosporidiosis. Arabidopsis thaliana is a small Eurasian annual flowering plant routinely used as an important model plant in molecular biology research and is reported to be edible (Lindh et al. 2008, Hansson et al. 2016). The extract from the green parts (leaves) of this plant was used as a control and we expected it to have a neutral effect on animal health and its parasitised gastric tissue, as we found only a few studies reporting the positive effect of $A$. thaliana seed extract.

The use of plant-derived products as antimicrobial agents has been investigated in depth. Isothiocyanates (ITCs) are bioactive products resulting from enzymatic hydrolysis of glucosinolates (GLs), the most abundant secondary metabolites in the plant order Brassicales. Although the antimicrobial activity of ITCs against foodborne and plant pathogens has been well documented, little is known about their antimicrobial properties against human pathogens (Romeo et al. 2018). Concurrently, during the trial finalisation in this study, an unexpected positive effect of A. thaliana plant extract on the reduction of spores of microsporidian Encephalitozoon cuniculi Levaditi, Nicolau et Schoen, 1923 in the tissues of experimentally inoculated BALB/c mice was documented (Mynářová 2015). Different genetic programs, activated upon pathogen recognition and leading to the production of inducible antimicrobial compounds, have been identified in this plant (Tierens et al. 2001). Using the fungus Neurospora crassa as a test organism, Tierens et al. (2001) analysed the antimicrobial compounds from aqueous extracts of leaves of Arabidopsis and suggested their role in the plant's protection against some pathogens. The treatment of mice with Alloxan-induced diabetes with A. thaliana at a dose of 200 $\mathrm{mg} / \mathrm{kg} \mathrm{BM}$ led to a significant reduction in blood glucose levels and an improvement in insulin resistance (Rashid et al. 2013, 2014; Taha et al. 2014). The consumption of $A$. thaliana reversed most of the histological changes in the liver of the diabetic mice, stimulated protein synthesis by increasing the number of ribosomes and significantly reduced oxidative stress in diabetes (= antioxidant effect) (Rashid et al. 2014). Moreover, as A. thaliana plants have a close relationship with species of Brassica eaten by humans it is of particular interest with respect to further investigations.

\section{Methods used for treatment efficacy evaluation: limitations in the screening of anti-cryptosporidial drugs.}

During the course of our experiments, we found a number of unexpected difficulties and limitations. One of these is the need for sufficient (preferably more than estimated) stocks of tested plant extracts for individual trials, which can be a problem in screening studies using exotic plants where their availability and quantity might be strictly limited (such as those used in our study). Primary screening of experimental protocols, therapeutic doses and the effectiveness of selected plant extracts in various solvent media consumes a lot of material before starting the animal experiments. Therefore, for pilot screening of the antiparasitic effect, it is preferable to use an in vitro system, at least for parasites where cultivation is possible (e.g. C. parvum). In vitro studies require smaller volumes of plant extracts and this approach helps to minimise the number of animals used and to reduce their distress during experiments.

Another issue was the variability of the course of infection in tested animals inoculated at the same doses, resulting in variations in oocyst shedding. Similarly to Sréter et al. (1995) relatively small numbers of animals are required for the estimation of the length of the prepatent period, but large numbers of animals are needed for the estimation of the mean of oocyst excretion. Additionally, histological observations of treatment effects during early stage cryptosporidiosis can be misleading, due to mild histopathological changes and the patchy occurrence of the parasite.

Promising reports from studies focusing on anti-cryptosporidial drug development are usually based on a reduction in oocyst shedding. The results of this study, however, indicate that the evaluation of parasitisation intensity based exclusively on the number of oocysts shed in faeces can be misleading. For example, despite a decline in oocyst shedding in some treatment groups (including those administered with Halocur), all known developmental stages of C. proliferans, from early stages invading epithelial cells, or freshly attached to the epithelium surface to oocysts enveloped by a parasitophorous sac, were observed in corresponding SEM and histological preparations. This means that despite the fact that fewer oocysts were excreted in host faeces, their development did not stop. Recently, it has been shown that rats infected with Cryptosporidium occultus Kváč, Vlnatá, Ježková, Horčičková, Konečný, Hlásková, McEvoy et Sak, 2018 shed fewer oocysts than would be predicted from the massive infection of the colonic epithelium (Kváč et al. 2018). This could be explained by the presence of two types of oocysts, i.e. thick- and thinwalled, in life cycle of $C$. proliferans and other species/ genotypes (Current and Reese 1986, Uni et al. 1987, Melicherová et al. 2014). It is likely that the treatment simply induces increased production of thin-walled oocysts, which excyst once they separate from host epithelium, are not usually excreted in faeces and appear to be responsible for autoinfection. The multiplication of cryptosporidia inside the same host via autoinfective oocysts (= sexual stage) appears to be beneficial for increasing parasite genetic variability, and thereby fitness and infectivity (Melicherová et 
al. 2014). Alternatively, the drug-affected parasite could begin investing in asexual multiplication and undergo multiple rounds of merogony I to produce high numbers of invasive merozoites. Autoinfection and the recycling of type I merogony provide an explanation for persistent chronic infections (Bouzid et al. 2013).

A further problem in similar studies is the correct choice of microscopic techniques for screening for parasite presence and morphopathological changes of the parasitised tissue. The surface topology detectable by SEM is insufficient for gastric cryptosporidia if not supplemented by histological sectioning as the mucus, a thick substance naturally produced by surface cells and cells of the gland necks to prevent self-digestion of the gastric mucosa, might hamper the view inside the gastric gland. This relatively thick layer, forming a non-transparent film after chemical fixation, is usually almost impossible to wash away, despite the careful and repetitive rinsing of stomach tissue (Melicherová et al. 2014). In addition, SEM analyses did not prove helpful in evaluating parasitisation intensity of gastric tissue, as it did not enable close examination of constricted or only slightly dilated pits. Transmission electron microscopy represents a powerful tool for evaluating pathological aspects along with the presence of parasites, but it is too expensive and time consuming for studies not focusing on ultrastructural aspects. Hence, to more accurately assess anti-cryptosporidial treatment efficacy in laboratory-housed animals, the most reliable and economic approach seems to be the monitoring of oocyst shedding accompanied by histological (gastric tissue) or SEM analysis (applicable for intestinal tissue) of the parasitised epithelium post mortem. Although such an approach is not applicable for medical purposes or for studies dealing with livestock, experimental studies on small laboratory animals based on the most accurate evaluation would provide important information on the actual effect of the drug tested.

Acknowledgements. The authors would like to acknowledge support from the Department of Botany and Zoology, Faculty of Science, Masaryk University, towards the preparation of this manuscript. The authors also to thank the State Ministry of Research and Technology (RISTEK) and the Directorate General of Forest Protection and Nature Conservation (PHKA) for their cooperation and for their permission to conduct research in Gunung Leuser National Park. The study was financially supported by the 'UMI - Saving of Pongidae' Foundation project 'Parasites and Natural Antiparasitics in the Orang-utan' and by the Czech Science Foundation (Grant No. P505/11/1163), by the Ministry of Education, Youth, and Sports, Czech Republic (Grant LO1204 from the National Program of Sustainability I). The authors would also like to thank Mallory Abel for editing and formatting the final draft.

\section{REFERENCES}

Abu El Ezz N.M.T., Khalil F.A.M., ShaApan R.M. 2011: Therapeutic effect of onion (Allium cepa) and cinnamon (Cinnamomum zeylanicum) oils on cryptosporidiosis in experimentally infected mice. Glob. Vet. 7: 179-183.

ANDERSON B.C. 1998: Cryptosporidiosis in bovine and human health. J. Dairy Sci. 81: 3036-3041.

Arrowood M.J., Sterling C.R. 1987: Isolation of Cryptosporidium oocysts and sporozoites using discontinuous sucrose and isopycnic Percoll gradients. J. Parasitol. 73: 314-319.

Bin-Hafeez B., Haque R., Parvez S., Pandey S., Sayeed I., RAISUDDIN S. 2003: Immunomodulatory effects of fenugreek (Trigonella foenum graecum L.) extract in mice. Int. Immunopharmacol. 3: 257-265.

Bouzid M., Hunter P.R., Chalmers R.M., Tyler K.M. 2013: Cryptosporidium pathogenicity and virulence. Clin. Microbiol. Rev. 26: $115-134$.

Castro I.C., Oliveira B.B., Slowikowski J.J., Coutinho B.P., Siqueira F.J.W., Costa L.B., Sevilleja J.E., Almeid C.A., Lima A.A., Warren C.A., others. 2012: Arginine decreases Cryptosporidium parvum infection in undernourished suckling mice involving nitric oxide synthase and arginase. $\mathrm{Nu}-$ trition 28: 678-685.

Causapé A.C., Sanchez-Acedo C., Quilez J., Del Cacho E., VIU M. 1999: Efficacy of halofuginone lactate against natural Cryptosporidium parvum infections in lambs. Res. Rev. Parasitol. 59: 41-46.

Chen X-M., Keithly J.S., Paya C.V., LaRusso N.F. 2002: Cryptosporidiosis. N. Engl. J. Med. 346: 1723-1731.

Current W.L., Reese N.C. 1986: A comparison of endogenous development of three isolates of Cryptosporidium in suckling mice. J. Protozool. 33: 98-108.

Díaz Peromingo J.A., Callejo A.M., Rodríguez J.G., González C.G., Lago M.A., Alvariño J.C., Sánchez P.S. 1999: Eradication of AIDS-related gastric cryptosporidiosis with azithromycin. Eur. J. Intern. Med. 10: 220-222.
Fareed G., Scolaro M., Jordan W., Sanders N., Chesson C., Seattery M., Long D., Castro C. 1996: The use of a highdose garlic preparation for the treatment of Cryptosporidium parvum diarrhea. In: Proceedings of the XI International Conference on AIDS in Vancouver, Canada, July 7-12, 1996, 11: 288

Fayer R., Morgan U., Upton S.J. 2000: Epidemiology of Cryptosporidium: transmission, detection and identification. Int. J. Parasitol. 30: 1305-1322.

Foitová I., Huffman M.A., Dušek L., Jarkovský J., Klapka R., OLŠAnskÝ M. 2010: Parasites species diversity and infection intensity of orangutan - Ecology factors with an emphasis on food items in their diets. In: Proceedings of the XXIII Congress of the International Primatological Society in Kyoto University, Kyoto, Japan, September 12-18, 2010, 26: 146

Foster J.C., Glass M.D., Courtney P.D., Ward L.A. 2003: Effect of Lactobacillus and Bifidobacterium on Cryptosporidium parvum oocyst viability. Food Microbiol. 20: 351-357.

GAAFAR M.R. 2012: Efficacy of Allium sativum (garlic) against experimental cryptosporidiosis. Alexandria J. Med. 48: 59-66.

GaRGALA G. 2008: Drug treatment and novel drug target against Cryptosporidium. Parasite 15: 275-281.

Giadinis N.D., Papadopoulos E., Lafi S.Q., Panousis N.K., Papazahariadou M., Karatzias H. 2008: Efficacy of halofuginone lactate for the treatment and prevention of cryptosporidiosis in goat kids: an extensive field trial. Small Ruminant Res. 76: 195-200.

Graczy T.K., Cranfield M.R., Hill S.L. 1996: Therapeutic efficacy of halofuginone and spiramycin treatment against Cryptosporidium serpentis (Apicomplexa: Cryptosporidiidae) infections in captive snakes. Parasitol. Res. 82: 143-148.

Grehan J.R., Schwartz J.H. 2009: Evolution of the second orangutan: phylogeny and biogeography of hominid origins. J. Biogeogr. 36: 1823-1844.

Hansson C., Schön K., Kalbina I., Strid Äke, Andersson S., Bokarewa M.I., Lycke N.Y. 2016: Feeding transgenic 
plants that express a tolerogenic fusion protein effectively protects against arthritis. Plant Biotechnol. J. 14: 1106-1115.

Jalovecká M., SaK B., KváČ M., Květoňová D., KuČerová Z., Salát J. 2010: Activation of protective cell-mediated immune response in gastric mucosa during Cryptosporidium muris infection and re-infection in immunocompetent mice. Parasitol. Res. 106: 1159-1166.

JirkŮ M., Valigurová A., Koudela B., Kř́ížek J., Modrý D., ŠLAPETA J. 2008: New species of Cryptosporidium Tyzzer, 1907 (Apicomplexa) from amphibian host: morphology, biology and phylogeny. Folia Parasitol. 55: 81-94.

Kilani R.T., Sekla L. 1987: Purification of Cryptosporidium oocysts and sporozoites by cesium chloride and Percoll gradients. Am. J. Trop. Med. Hyg. 36: 505-508.

Kobayashi C., Yokoyama H., Van Nguyen S., Kodama Y, Kimata T., IzeKi M. 2004: Effect of egg yolk antibody on experimental Cryptosporidium parvum infection in SCID mice. Vaccine 23: 232-235.

Kváč M., Havrdová N., Hlásková L., DañKová T., Kanděra J., JežKová J., Vítovec J., Sak B., Ortega Y., Xiao L., Modrý D., Chelladurai J.R., Prantlová V., McEvoy J. 2016: Cryptosporidium proliferans $\mathrm{n}$. sp. (Apicomplexa: Cryptosporidiidae): molecular and biological evidence of cryptic species within gastric Cryptosporidium of mammals. PloS ONE 11: e0147090.

KváČ M., KodádKová A., SAK B., Květoňová D., Jalovecká M., Rost M., Salát J. 2011: Activated CD8+ T cells contribute to clearance of gastric Cryptosporidium muris infections. Parasite Immunol. 33: 210-216.

Kváč M., OndráčKová Z., Květoñová D., SAK B., Vítovec J. 2007: Infectivity and pathogenicity of Cryptosporidium andersoni to a novel host, southern multimammate mouse (Mastomys coucha). Vet. Parasitol. 143: 229-233.

KváČ M., SAK B., Květoñová D., Ditrich O., Hofmannová L., Modrý D., Vítovec J., Xiao L. 2008: Infectivity, pathogenicity, and genetic characteristics of mammalian gastric Cryptosporidium spp. in domestic ruminants. Vet. Parasitol. 153: 363-367.

Kváč M., Vlnatá G., JežKová J., HorčičKová M., KoneČnÝ R. Hlásková L., McEvoy J., SAK B. 2018: Cryptosporidium occultus sp. n. (Apicomplexa: Cryptosporidiidae) in rats. Eur. J. Protistol. 63: 96-104.

Lindh I., Kalbina I., Thulin S., Scherbak N., Sävenstrand H., BrÅve A., Hinkula J., Strid Å., Andersson S. 2008: Feeding of mice with Arabidopsis thaliana expressing the HIV-1 subtype C p24 antigen gives rise to systemic immune responses. APMIS 116: 985-994.

Masuno K., Yanai T., Hirata A., Yonemaru K., Sakai H., Satoh M., Masegi T., NaKai Y. 2006: Morphological and immunohistochemical features of Cryptosporidium andersoni in cattle. Vet. Pathol. 43: 202-207.

Melicherová J., Ilgova J., Kváč M., SaK B., Koudela B. Valiguroví A. 2014: Life cycle of Cryptosporidium muris in two rodents with different responses to parasitisation. Parasitology 141: 287-303.

Melicherová J., Mazourová V., Valigurová A. 2016: In vitro excystation of Cryptosporidium muris oocysts and viability of released sporozoites in different incubation media. Parasitol. Res. 115: 1113-1121.

MiLÁČEK P., Vítovec J. 1985: Differential staining of cryptosporidia by aniline-carbol-methyl violet and tartrazine in smears from faeces and scrapings of intestinal mucosa. Folia Parasitol. 32: 50 .

Moore D., Waters W.R., Wannemuehler M.J., Harp J.A. 2001: Treatment with agmatine inhibits Cryptosporidium parvum infection in infant mice. J. Parasitol. 87: 211-213.

Morrogh-Bernard H., Foitová I., Yeen Z., Wilkin P., De Martin R., Rárová L., Doležal K., Nurcahyo W., OLŠANSKÝ M. 2017: Self-medication by orang-utans (Pongo pygmaeus) using bioactive properties of Dracaena cantleyi. Sci. Rep. 7: 16653.
MynáŘová A. 2015: The prevalence and diversity of Cryptosporidium, Giardia and microsporidia in orangutans (Pongo spp.) and the effect of selected plant extracts on the course of experimental infection with Encephalitozoon cuniculi in BALB/c mice. University of South Bohemia in České Budějovice, 106 pp, Master's thesis. (In Czech)

Nakamura A.A., Meireles M.V. 2015: Cryptosporidium infections in birds - a review. Rev. Bras. Parasitol. Vet. 24: 253-267.

O'Donoghue P.J. 1995: Cryptosporidium and cryptosporidiosis in man and animals. Int. J. Parasitol. 25: 139-195.

Ortega-Pierres G., Cacciò S., Fayer R., Mank T.G., Smith H.V., Thompson R.C.A. (EDs.) 2009: Giardia and Cryptosporidium: From Molecules to Disease. CABI, Wallingford, 520 pp.

Pecková R., Doležal K., Sak B., Květoňová D., Kváč M., Nurcahyo W., Foitová I. 2018: Effect of Piper betle on Giardia intestinalis infection in vivo. Exp. Parasitol. 184: 39-45.

Perrucci S., Fichi G., Buggiani C., Rossi G., Flamini G. 2006: Efficacy of mangiferin against Cryptosporidium parvum in a neonatal mouse model. Parasitol. Res. 99: 184-188.

Petermann J., Paraud C., Pors I., Chartier C. 2014: Efficacy of halofuginone lactate against experimental cryptosporidiosis in goat neonates. Vet. Parasitol. 202: 326-329.

Pickerd N., Tuthill D. 2004: Resolution of cryptosporidiosis with probiotic treatment. Postgrad. Med. J. 80: 112-113.

Ramsay D.B., Long S.E., Ali M.A., Entwisle C., Orenstein J.M., Rossi C., Borum M.L. 2007: Isolated gastric cryptosporidiosis in an immunocompetent patient. Dig. Dis. Sci. 52: 1364-1366.

Rashid K.I., Aljibouri A.M., Zayer A.J., Khalid L.B., АвDul-Munaem A. 2013: Study the effect of Arabidopsis thaliana extract on reducing blood glucose level in diabetic white albino mice. Iraqi J. Pharm. Sci. 22: 115-119.

Rashid K.I., Kamel A.M., BaKir T.Y. 2014: Preventative effects of Arabidopsis thaliana extract on liver damage of diabetic mice induced by Alloxan. J. Pharm. Res. 4: 82-86.

Rivasi F., Rossi P., Righi E., Pozio E. 1999: Gastric cryptosporidiosis: correlation between intensity of infection and histological alterations. Histopathology 34: 405-409.

Romeo L., Iori R., Rollin P., Bramanti P., Mazzon E. 2018: Isothiocyanates: an overview of their antimicrobial activity against human infections. Molecules 23: 624.

Rotkiewicz T., Rotkiewicz Z., Depta A., Kander M. 2001: Effect of Lactobacillus acidophilus and Bifidobacterium sp. on the course of Cryptosporidium parvum invasion in new-born piglets. Bull. Vet. Inst. Pulawy 45: 187-196.

Ryan U. 2010: Cryptosporidium in birds, fish and amphibians. Exp. Parasitol. 124: 113-120.

Shahiduzzaman M., Dyachenko V., Khalafalla R.E., DeSOUKy A.Y., Daugschies A. 2009: Effects of curcumin on Cryptosporidium parvum in vitro. Parasitol. Res. 105: 1155-1161.

Squires J.M., Ferreira J.F., Lindsay D.S., ZajaC A.M. 2011: Effects of artemisinin and Artemisia extracts on Haemonchus contortus in gerbils (Meriones unguiculatus). Vet. Parasitol. 175: 103-108.

SrÉTER T., VArga I., BÉKÉSI L. 1995: Age-dependent resistance to Cryptosporidium baileyi infection in chickens. J. Parasitol. 81: 827-829.

Taha M.A., Ahmed S.J., Rashid K.I. 2014: Histological study on the effect of Arabidopsis thaliana extraction on Alloxan-induced diabetic infertility mice. Int. J. Drug. Discov. 6: 207-212.

Tarantino C., Flamini G., Perrucci S. 2004: Anticryptosporidial activity of some extracts of Santolina ligustica and Centaurea horrida and of Mangiferin. Parassitologia 46: 130-131.

Tatar G., HaziroĞLu R., Hascelik G. 1995: Helicobacter felis as a cofactor alone or together with stress in cryptosporidial activation in mice. J. Int. Med. Res. 23: 473-479.

Taylor M.A., Marshall R.N., Green J.A., Catchpole J. 1999: The pathogenesis of experimental infections of Cryptosporidium muris (strain RN 66) in outbred nude mice. Vet. Parasitol. 86: 41-48. 
Thompson R.C.A., Olson M.E., Zhu G., Еnomoto S., Aвrahamsen M.S., HiJjawi N.S. 2005: Cryptosporidium and cryptosporidiosis. Adv. Parasitol. 59: 77-158.

Tierens K.F., Thomma B.P., Brouwer M., Schmidt J., Kistner K., Porzel A., Mauch-Mani B., Cammue B.P., BroeKAERT W.F. 2001: Study of the role of antimicrobial glucosinolate-derived isothiocyanates in resistance of Arabidopsis to microbial pathogens. Plant Physiol. 125: 1688-1699.

Tyzzer E.E. 1910: An extracellular coccidium, Cryptosporidium muris (gen. et sp. nov.) of the gastric glands of the common mouse. J. Med. Res. 23: 487-510.

TzIPORI S. 1998: Cryptosporidiosis: laboratory investigations and chemotherapy. Adv. Parasitol. 40: 187-221.

Uni S., Iseki M., Maekawa T., Moriya K., Takada S. 1987: Ultrastructure of Cryptosporidium muris (strain RN 66) parasitising the murine stomach. Parasitol. Res. 74: 123-132.

Val-Bernal J.F., Mayorga M., Azueta A., Cabezas J., LozaNO J.L., Fernández F. 2013: AIDS-related gastric cryptosporidiosis simulating malignancy. Rev. Esp. Patol. 46: 247-251.
Valigurová A., Hofmannová L., Koudela B., Vávra J. 2007: An ultrastructural comparison of the attachment sites between Gregarina steini and Cryptosporidium muris. J. Eukaryot. Microbiol. 54: 495-510.

Valigurová A., Jirků M., Koudela B., Gelnar M., Modrý D., ŠLAPETA J. 2008: Cryptosporidia: epicellular parasites embraced by the host cell membrane. Int. J. Parasitol. 38: 913-922.

Ventura G., Cauda R., Larocca L.M., Riccioni M.E., TumBarello M., Lucia M.B. 1997: Gastric cryptosporidiosis complicating HIV infection: case report and review of the literature. Eur. J. Gastroenterol. Hepatol. 9: 307-310.

Wu L., Jiang X., Shen Y., Lu Z., Tu G., Fu X., Chen S., CaO J. 2011: Efficacy of ginkgolic acids against Cryptosporidium andersoni in cell culture. Parasitol. Res. 109: 1475.

Yoshimi N., Matsunaga K., Katayama M., Yamada Y., Kuno T., Qiao Z., Hara A., Yamahara J., Mori H. 2001: The inhibitory effects of mangiferin, a naturally occurring glucosylxanthone, in bowel carcinogenesis of male F344 rats. Cancer Lett. 163: 163-170.

Cite this article as: Valigurová A., Pecková R., Doležal K., Sak B., Květoňová D., Kváč M., Nurcahyo W., Foitová I. 2018: Limitations in the screening of potentially anti-cryptosporidial agents using laboratory rodents with gastric cryptosporidiosis. Folia Parasitol. 65: 010 